\title{
Ionizing Radiation Technologies to Increase the Extraction of Bioactive Compounds from Agro-Industrial Residues: A Review
}

\author{
Joana Madureira, Lillian Barros, Sandra Cabo Verde,* Fernanda M. A. Margaça, Celestino Santos-Buelga,
} and Isabel C. F. R. Ferreira*

Cite This: J. Agric. Food Chem. 2020, 68, 11054-11067

Read Online

ACCESS 1

山ll Metrics \& More

回 Article Recommendations

ABSTRACT: Due to the growing demand in society for healthier foods, scientific communities are searching and developing new ingredients. In this context, agro-industrial residues, which can have a negative impact on the environment, represent a natural source for bioactive compounds and their recovery can contribute to economic and environmental sustainability. Ionizing radiation is a clean and eco-friendly technology that can be used to improve the extraction of bioactive compounds. The aim of this review, after presenting general aspects about bioactive compounds in agro-industrial residues and radiation technologies, is to focus on the effects of ionizing radiation on the extraction of bioactive compounds from these residues and related bioactive properties. Irradiated residues were demonstrated to have enhanced bioactive characteristics that turn the prepared extracts suitable for applications in food industry, resulting in high-added-value products as well as reducing adverse impacts on the environment.

KEYWORDS: agro-industrial residues, extraction, bioactive compounds, bioactivities, ionizing radiation

\section{INTRODUCTION}

The agro-industrial residues can be many and different wastes from agriculture and industry. Agriculture residues can be divided into field residues and process residues and can include leaves, stalks, seedpods, stems, molasses, husks, pulp, and peels. ${ }^{1}$ These wastes can also comprise the byproducts of the agro-food industry such as oil cakes from oil extraction, degummed fruits and legumes, coffee dregs, milk serum, sludge from wool, cellulose, bran, starch, juice, and sugars. ${ }^{2}$

With the fast developing world, the high volume of wastes produced by these industries generates large quantities for disposal and represents a loss of underutilized biomass and nutrients. Although some of them can be discharged safely, others are considered to have harmful effects on the environment with consequences to human and animal health. This problem imposes the need to find strategies to reuse the valuable agro-industrial residues in a more efficient way, providing environmental benefits and contributing to the economic sustainability. The agro-industrial residues can be used as fertilizers in agriculture, biofuel and enzyme production, preparation of biodegradable polymeric systems, recycled agricultural composting and extraction of food flavoring, preservative and bioactive compounds. ${ }^{3}$

Nowadays, consumers are more conscious and interested in what they eat, thus increasing the demand for healthier foodstuffs. ${ }^{4}$ In this way, the food industry tried to answer this challenge and started to develop innovative and natural functional products ${ }^{5}$ that could be used to replace the existing synthetic ones or as new added-value ingredients. The extractable antioxidant and antimicrobial compounds from agro-industrial residues offer a more natural and safer alternative to the food industry. ${ }^{6}$
The purpose of this review is to provide an overview of the bioactive compounds recovery from agro-industrial wastes to develop functional/health foods. The current status of the extraction of agro-industrial bioactive compounds is summarized, and for the first time, we discuss the positive impact of the ionizing radiation technology on the extractability of these compounds.

\section{EXTRACTION OF BIOACTIVE COMPOUNDS}

Bioactive compounds are components naturally present in plant and food products that provide health benefits and wellness, including antioxidant, anti-inflammatory, antimicrobial, anticancer, and immunomodulatory activities. ${ }^{7}$ Natural bioactive compounds have diverse structures and functionalities with molecules having enormous potential for the production of nutraceuticals, functional foods, and food additives. ${ }^{8}$ With this purpose, these compounds are being intensively studied to evaluate their effects on health, showing benefic effects for cardiovascular disease, cancers, and others. They comprise compounds with different chemical structures (hydrophilic or lipophilic), distribution in nature, range of concentrations, possible site of action, effectiveness against oxidative species, specificity, and biological action. The main classes of bioactive compounds include polyphenolic compounds, carotenoids, tocopherols, phytosterols, organosulfur

Received: August 4, 2020

Revised: September 15, 2020

Accepted: September 16, 2020

Published: September 16, 2020 
compounds, fatty acids, betalains, essential oils (terpenes), and alkaloids. ${ }^{7}$

The extraction of these compounds can be performed by using conventional and nonconventional methods. Conventional techniques are based on solid-liquid extraction requiring the use of organic solvents, temperature, and agitation and include percolation, maceration (ME), decoction, and hydrodistillation. Some extraction variables such as type of solvent and product/solvent ratio, time and temperature of extraction, and mode of stirring are significant influencing factors on the recovery of bioactive compounds and should be considered in the process optimization.?

To overcome limitations of conventional methods, such as long extraction time, requirement of costly, high purity, and safe solvents, evaporation of the large amount of solvent, and/ or low extraction selectivity, new and promising techniques have been introduced ${ }^{10,11}$ such as ultrasound-assisted extraction (UAE), ${ }^{12,13}$ pulsed electric field (PEF) extraction, ${ }^{14,15}$ enzyme-assisted extraction (EAE) ${ }^{16-18}$ microwave-assisted extraction (MAE), ${ }^{19,20}$ pressurized liquid extraction (PLE), ${ }^{21}$ supercritical fluid extraction (SFE), ${ }^{22}$ pressurized low-polarity water extraction, and molecular distillation. M'hiri, Ioannou, Paris, Ghoul, and Boudhrioua $(2016)^{23}$ compared the efficiencies of different methods (ME, UAE, MAE, high pressure extraction ( $\mathrm{HPE}$ ), and supercritical $\mathrm{CO}_{2}$ extraction $\left(\mathrm{SC}-\mathrm{CO}_{2}\right)$ ) for antioxidant extraction from Citrus sinensis (L.) Osbeck peel, evaluating selectivity, total phenol content, total and individual flavonoids, and antioxidant activity; they concluded that MAE was the extracting method to obtain higher contents of phenols, flavonoids, and individual flavonoids. Tabaraki and Ghadiri $(2016)^{24}$ also obtained the best results on the extraction of antioxidants from Pistacia vera L. hull using MAE when compared with UAE and conventional extraction. Vieira et al. (2017) ${ }^{25}$ compared conventional maceration and MAE for the extraction of valuable compounds from Juglans regia $\mathrm{L}$. leaves, also attributing to MAE better outcomes. On the other hand, UAE using acidified waterethanol mixtures as solvent was considered the optimal technique to extract bioactive anthocyanin pigments from Ficus carica L. peel, when compared with heat-assisted extraction (HAE) and MAE. ${ }^{26}$ In another study, the multifrequency multimode modulated (MMM) ultrasonic technique increased the recovery of phenolic compounds from olive pomace and its antioxidant activity when compared to the conventional extraction. ${ }^{27}$

In general, although the results regarding the technique of choice differ depending on the study, the assisted extraction methods showed to be more effective than the conventional ones to extract polyphenol antioxidants from agricultural byproducts.

\section{ISOLATION AND CHARACTERIZATION OF BIOACTIVE COMPOUNDS}

After extraction, the obtained extracts contain complex mixtures of natural compounds that have to be isolated, purified, and further characterized. The development of efficient methods for isolation/purification/characterization of the bioactive compounds has been an important challenge for researchers, which depends on the chemical and physical characteristics of them. ${ }^{28,29}$

The isolation and purification of the compounds involves different chromatographic techniques, such as thin-layer chromatography (TLC), column chromatography, flash chromatography, and high-performance liquid chromatography (HPLC). TLC is a simple, cost-effective, and rapid chromatographic technique, which gives the number of components present in the mixture but can also identify the compound comparing with a standard one, and HPLC is a versatile and widely used technique for the isolation of compounds from agro-industrial residues. ${ }^{30}$

The structure and biological activity of the purified compounds are then determined using different methodologies. Fourier transform infrared spectroscopy (FTIR) can be considered as a fingerprinting tool due to their unique spectra of pure compounds, allowing the identification of functional groups present in a compound. ${ }^{31}$ Furthermore, HPLC can be coupled with simple detectors, such as UV detectors, or detectors for hyphenated systems, such as UVdiode array (DAD), mass spectrometry (MS), or nuclear magnetic resonance (NMR), producing multidimensional data for online identification and dereplication purposes. ${ }^{29}$ An overview of the employed methodologies in extraction, isolation, and characterization of bioactive compounds from residues of agro-food industries can be found in Figure 1.

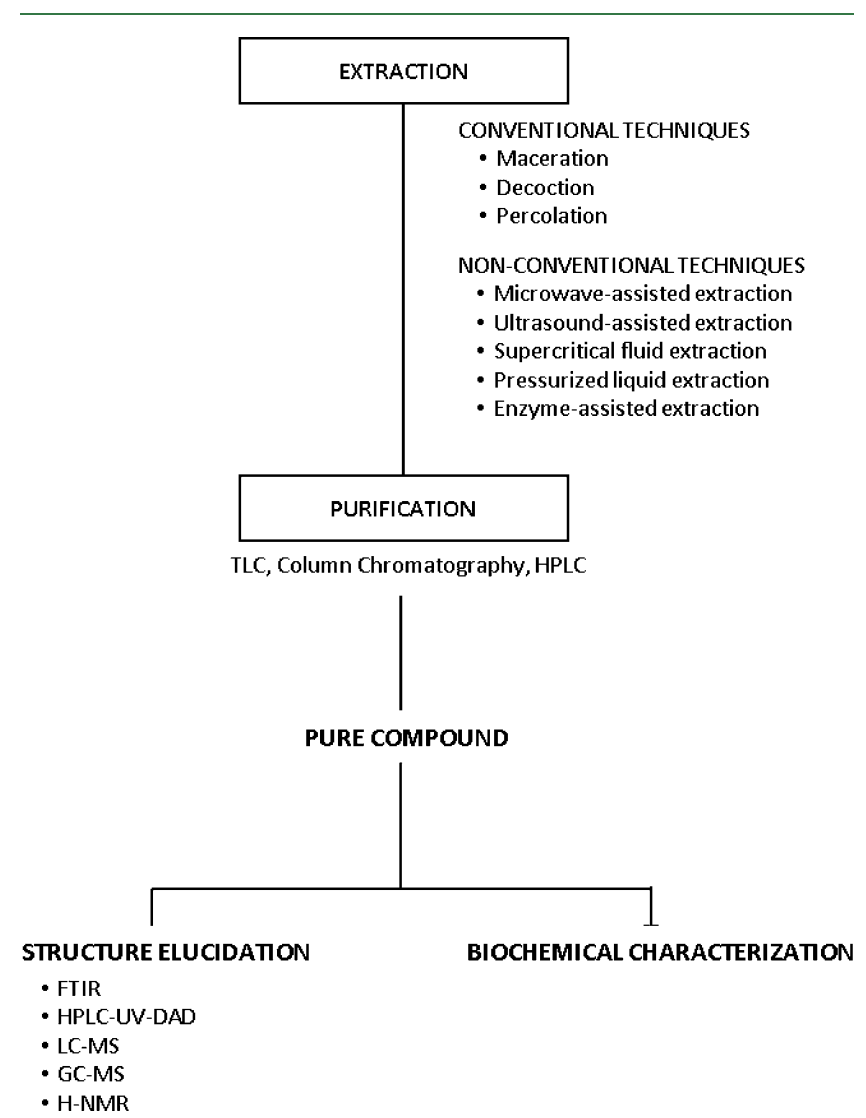

Figure 1. Methodologies used in extraction, isolation, and characterization of bioactive compounds from agro-industrial residues.

These techniques can be combined in order to provide a rapid and accurate identification of compounds, especially when the pure compound is unknown and not available. Hence, it is important to precisely select the methods to use from the extraction to the separation and purification, as this is crucial to obtain accurate results. 


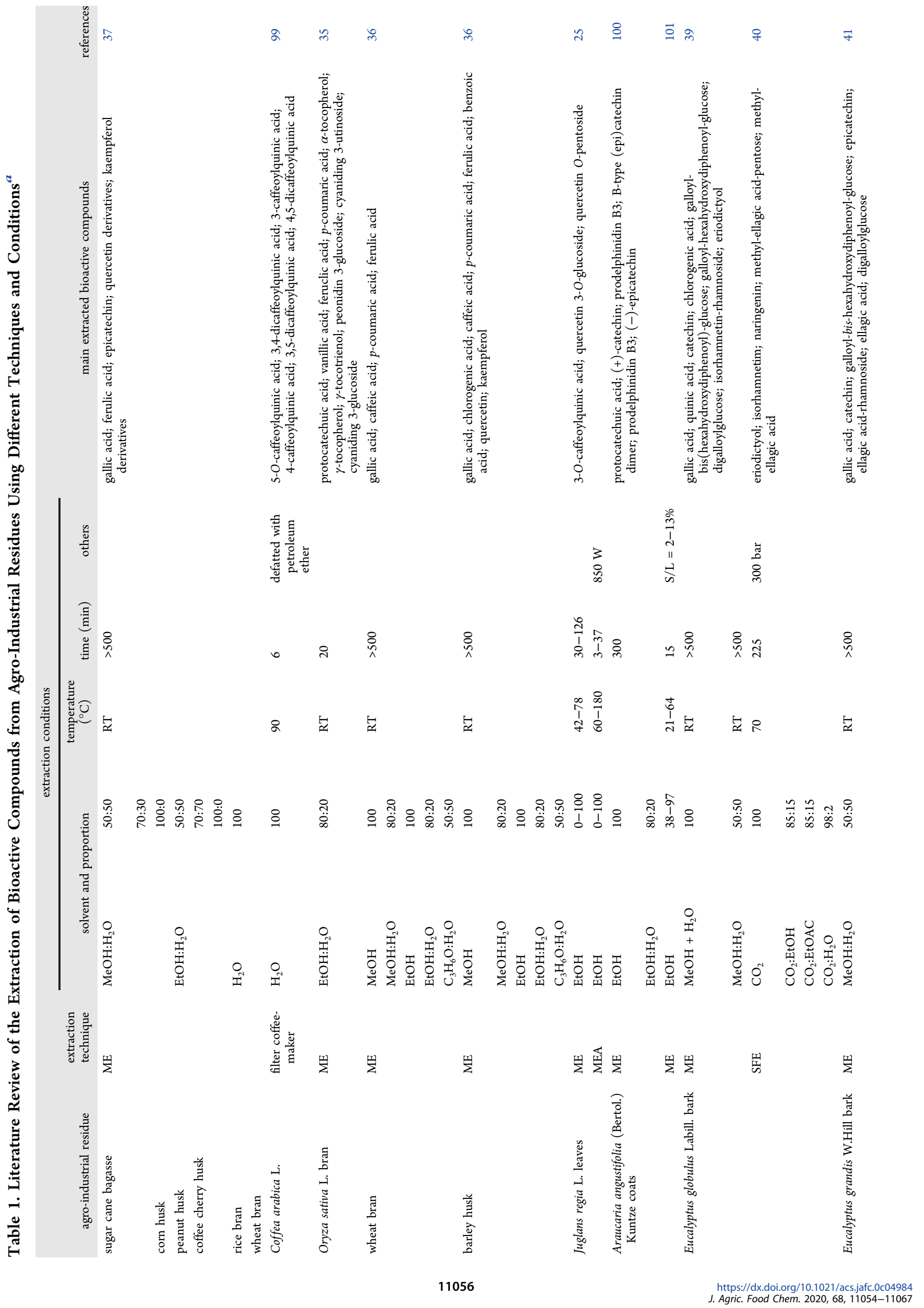









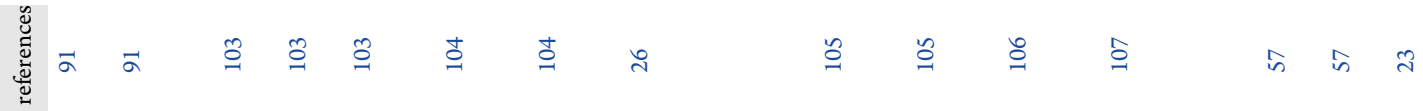
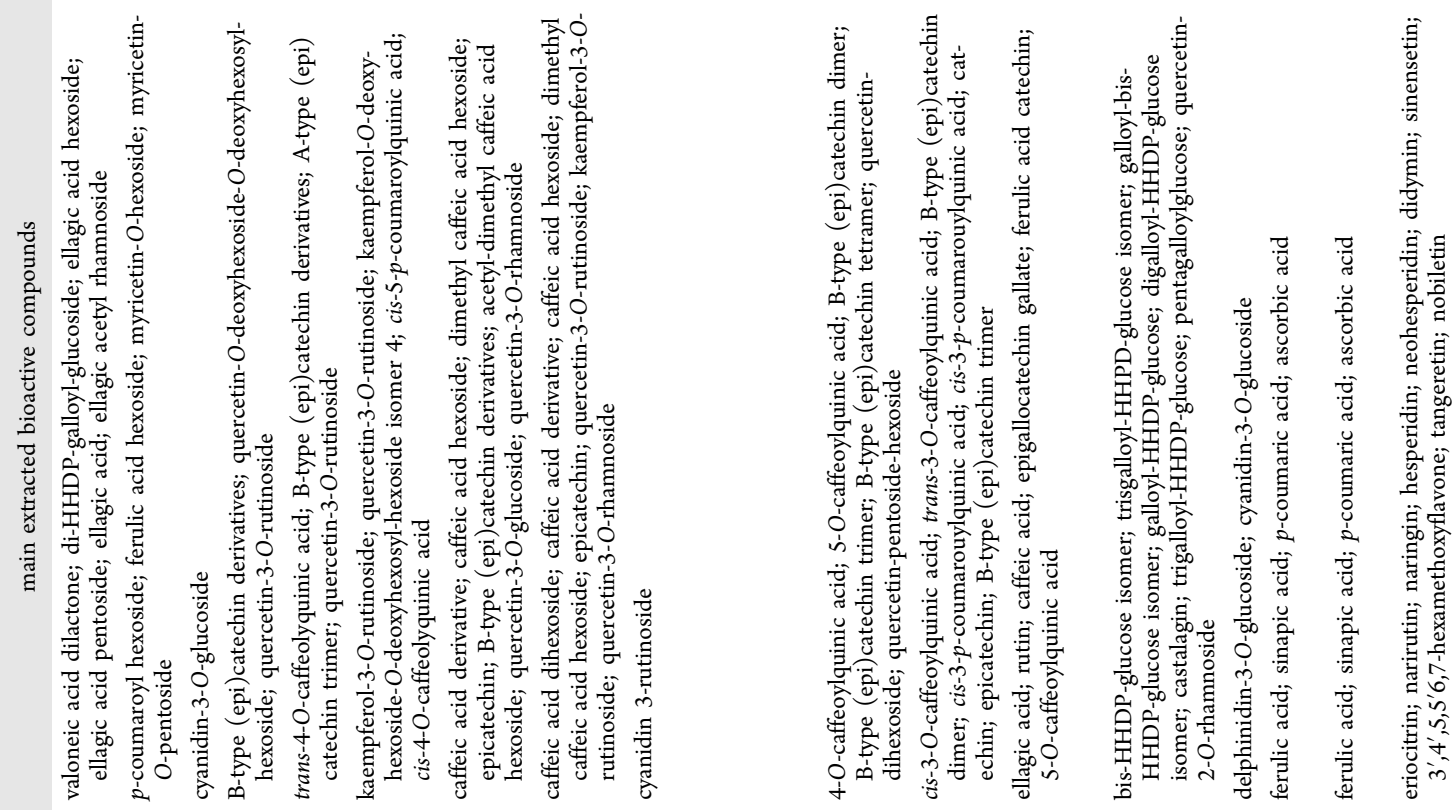

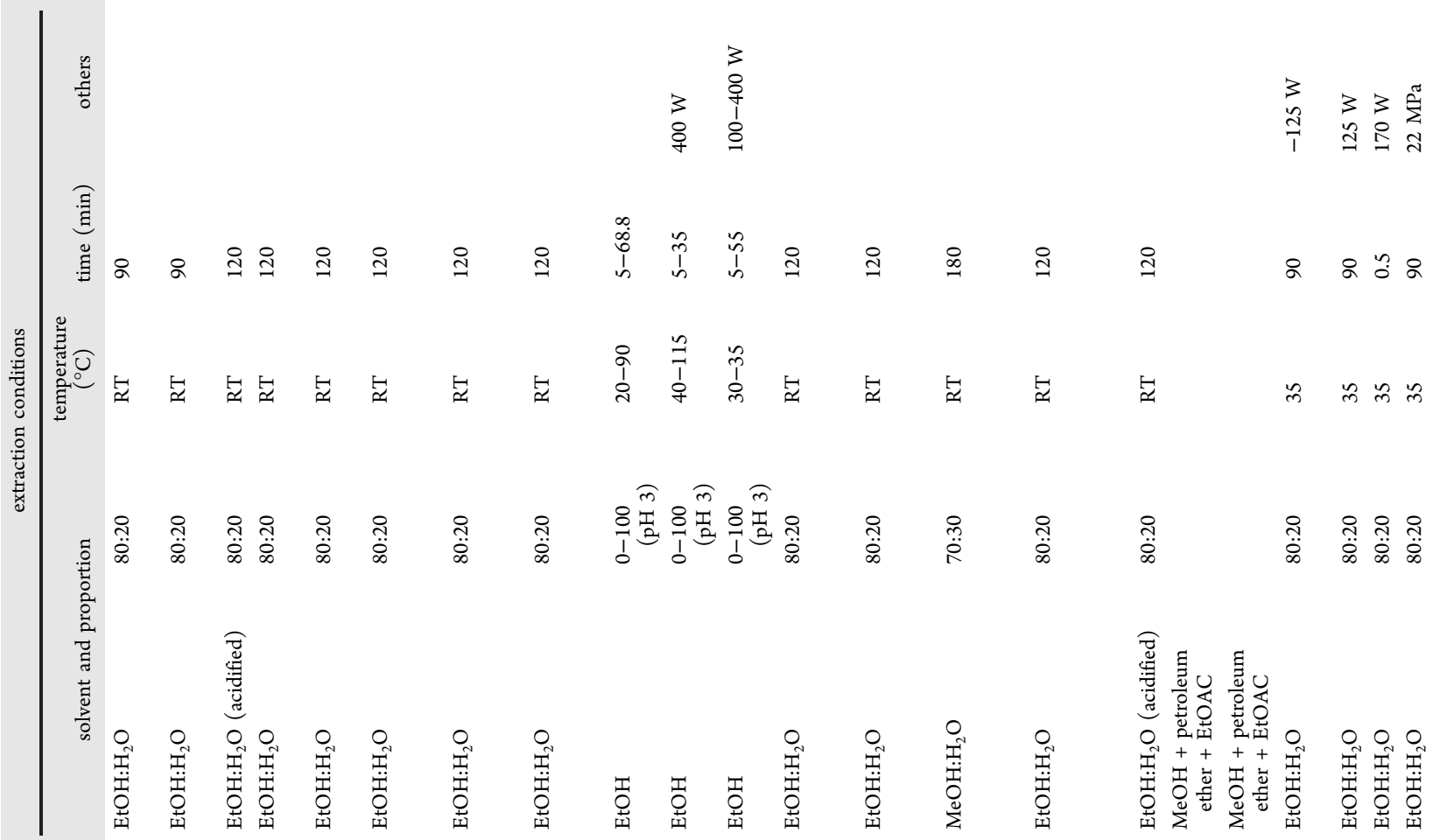

密

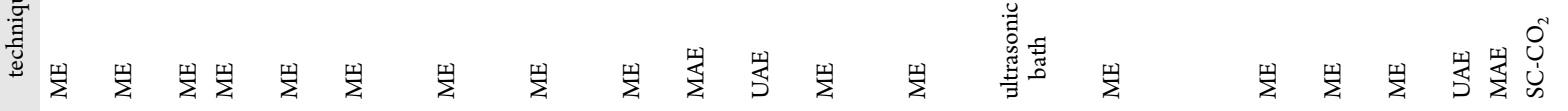

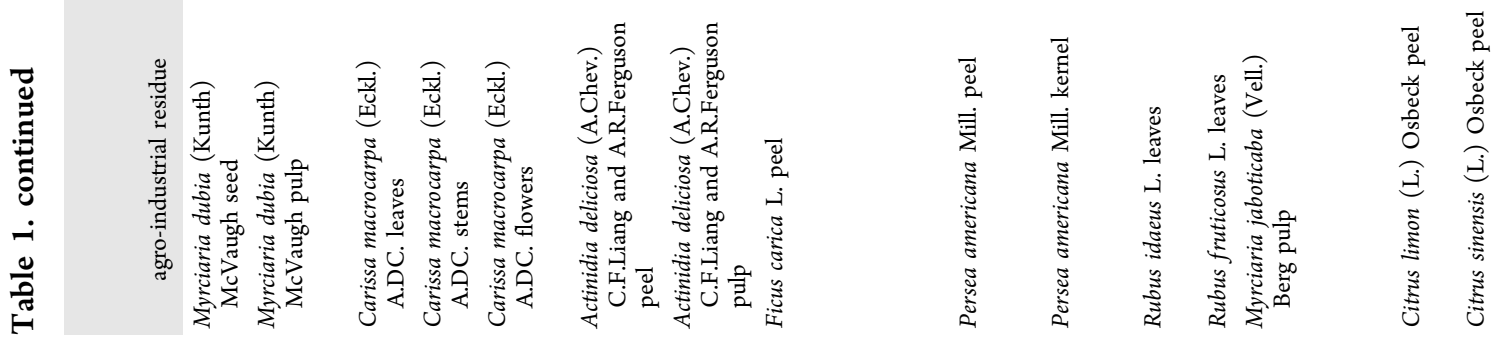


逆

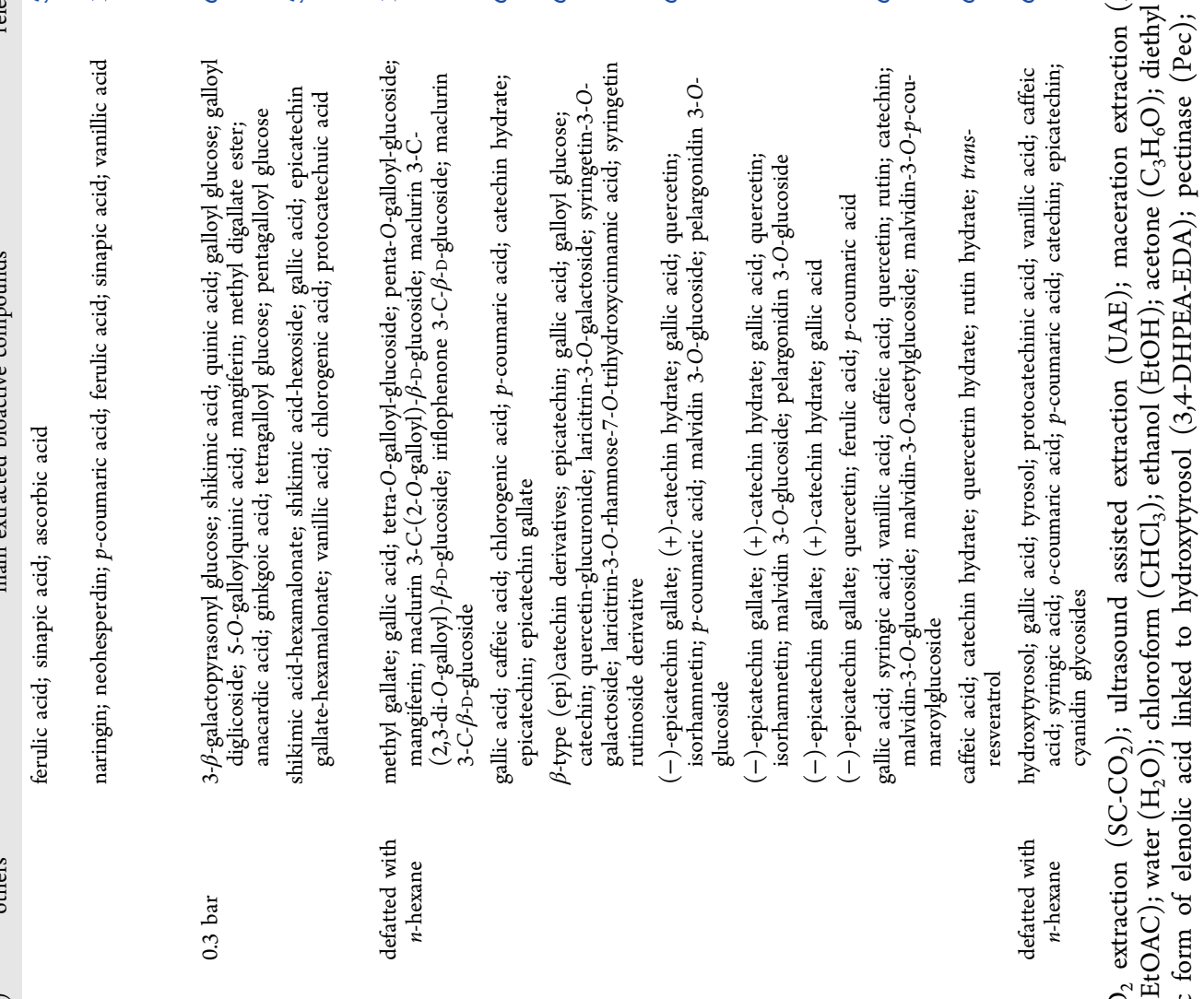

言
苛

\&

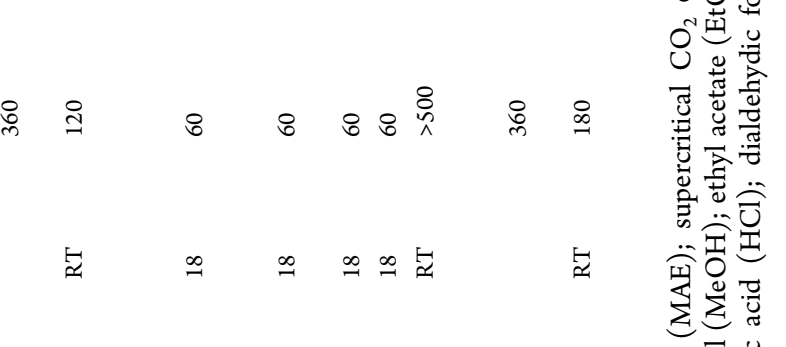

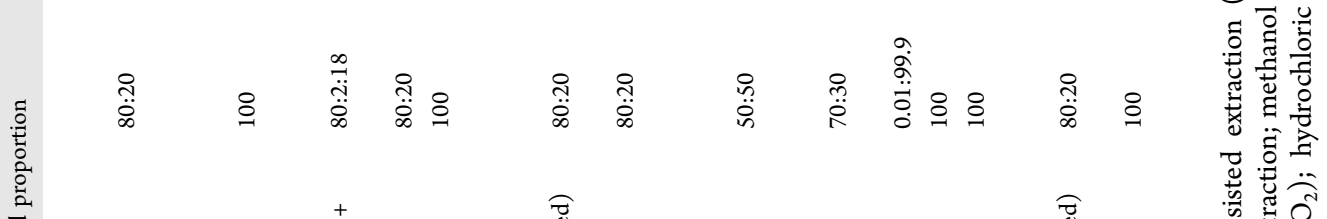

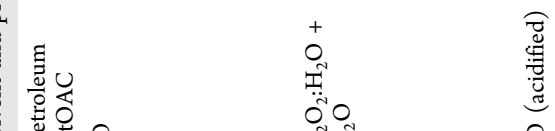

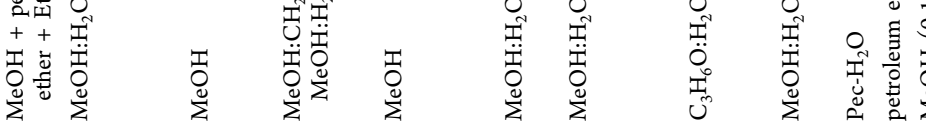

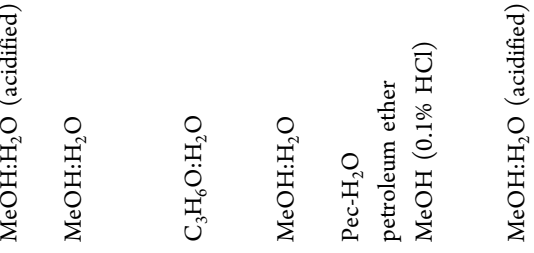

:

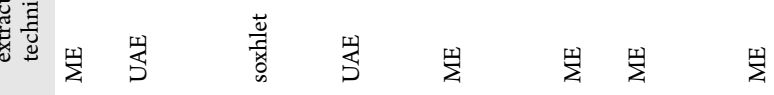

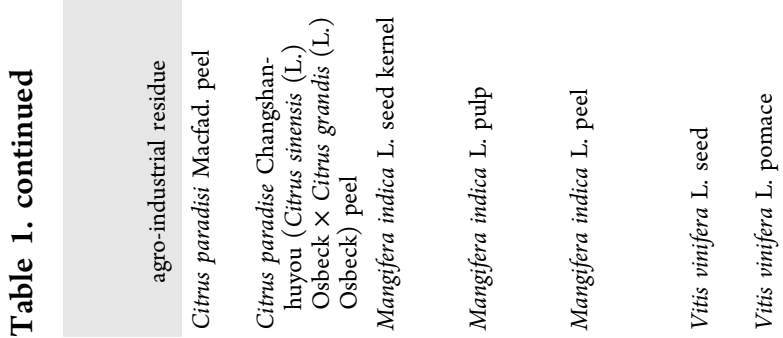

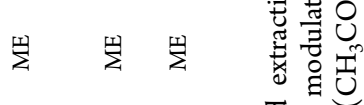

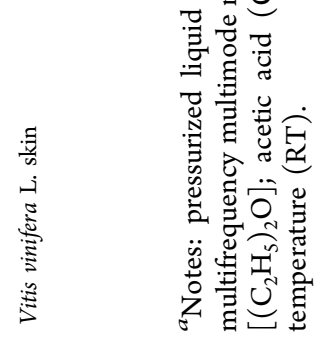




\section{BIOACTIVE COMPOUNDS IN AGRO-INDUSTRIAL RESIDUES}

Agro-industrial residues have been explored as a source of natural bioactive compounds, such as flavonoids, phenolic acids (e.g., hydroxycinnamic and hydroxybenzoic acid derivatives), tannins, carotenoids, tocopherols, phytosterols, or arabinoxylans. These bioactive compounds exhibit a wide range of potential healthy properties including antiallergenic, antiatherogenic, anti-inflammatory, antimicrobial, anticarcinogenic, antithrombotic, antioxidant, cardioprotective, vasodilatory, or prebiotic effects, among others. ${ }^{32,33}$ Numerous examples of the extraction of bioactive compounds from agroindustrial wastes can be found in the literature, as summarized in Table 1.

Phenolic compounds with antioxidant potential have been identified in agricultural residues, such as sugar cane bagasse, corn husk, peanut husk, coffee cherry husk, rice bran, or wheat bran. $^{34-37}$ Vijayalaxmi et al. $(2015)^{37}$ identified five compounds as the major bioactive compounds present in most of these residues: gallic acid, ferulic acid, epicatechin, quercetin, and kaempferol derivatives. Huang and Lai $(2016)^{35}$ established the profiles of bioactive compounds of outer and inner O. sativa L. bran from six colored rice samples, detecting protocatechuic, vanillic, ferulic, and $p$-coumaric acids as the most abundant phenolic acids present and $\alpha$ - and $\gamma$ tocopherols and $\gamma$-tocotrienol as the main vitamin $\mathrm{E}$ components. The major anthocyanins present in both black and red $O$. sativa $\mathrm{L}$. were peonidin 3-glucoside, cyanidin 3rutinoside, and cyanidin 3-glucoside.

A detailed work about the most abundant phenolic compounds in cork and pulp industrial residues was developed by S. A. O. Santos and co-workers. ${ }^{38-41}$ The barks of Eucalyptus globulus Labill., Eucalyptus grandis W.Hill., Eucalyptus urograndis (E. grandis W.Hill. $\times$ E. urophylla S.T.Blake), and Eucalyptus maidenii F.Muell. as well as the cork from Quercus suber L. and its byproducts (cork powder and black condensates) are constituted by different types of phenolic compounds. Epicatechin and quercetin-glucuronide were revealed as the major phenolic compounds in E. grandis and E. urograndis bark, followed by ellagic acid-rhamnoside and ellagic acid in E. grandis and by galloyl-bis-hexahydroxydiphenoyl (HHDP)-glucose and gallic acid in E. urograndis. Catechin, chlorogenic acid, and methyl-ellagic acid-pentose were the major compounds in E. maidenii bark. Moreover, ellagic acid-rhamnoside, dihydroxy-isopropylchromone-hexoside, and dihydroxy-(methylpropyl)isopropylchromone-hexoside were referenced for the first time in these species. ${ }^{41}$ Santos et al. $(2011)^{39}$ obtained the phenolic profile of E. globulus bark using different solvents (methanol, water, and methanol/ water), with methanol/water mixtures being the most efficient to isolate polyphenols. Digalloylglucose was identified as the major compound in the methanol and methanol/water extracts, followed by isorhamnetin-rhamnoside in the methanol extract and by catechin in the methanol/water extract, whereas in the water extract catechin and galloyl-HHDP-glucose were identified as the predominant components. Other compounds were referenced for the first time as constituents of E. globulus bark, namely, quinic, dihydroxyphenylacetic, and caffeic acids, bis(hexahydroxydiphenoyl (HHDP))-glucose, galloyl-bis(HHDP)-glucose, galloyl-HHDP-glucose, isorhamnetin-hexoside, quercetin-hexoside, methylellagic acid (EA)-pentose conjugate, myricetin-rhamnoside, isorhamnetin-rhamnoside, mearnsetin, phloridzin, mearnsetin-hexoside, luteolin, and a proanthocyanidin B-type dimer. In another work, Santos, Villaverde, and Silva et al. (2012) ${ }^{40}$ analyzed the supercritical fluid extraction of phenolic compounds from E. globulus bark, using supercritical $\mathrm{CO}_{2}$ alone and modified with water, ethyl acetate, and ethanol. In terms of the extraction yield and antioxidant activity of phenolic components, the best results were achieved with $\mathrm{CO}_{2} / \mathrm{EtOH}$, recovering much higher quantities of eriodictyol, naringenin, and isorhamentin than in the conventional solid/liquid extracts obtained before.

The major components identified in the cork from Quercus suber L. were ellagic acid, followed by gallic, protocatechuic, and caffeic acids and esculetin. ${ }^{38}$ Those authors identified for the first time salicylic acid, eriodictyol, and quinic acid in cork extracts. Another byproduct from the cork industry is the effluent generated from the plank immersion on boiled water to improve characteristics such as elasticity and homogeneity and to make it flat. This wastewater also contains considerable amounts of phenolic compounds, namely, tannins and phenolic acids, such as gallic, protocatechuic, syringic, ferulic, and ellagic acids. ${ }^{42}$

From the cocoa and chocolate industry, the main byproducts obtained from the cocoa bean are pod husks, bean shells, and mucilage, which are recognized as important sources of bioactive compounds. ${ }^{43}$ Phenolic compounds recovered from Theobroma cacao L. pod husk mostly consist of catechin, quercetin, epicatechin, and gallic, coumaric, and protocatechuic acids ${ }^{43}$ and also flavonols (kaempferol) and flavones (linarin). ${ }^{44}$

The wastes generated in the olive oil industry are also important sources of phenolic compounds $27,45-54$ with antiproliferative and antimicrobial properties. ${ }^{46,48,51}$ Besides differences in the olive oil extraction technique, the phenolic composition of the olive wastes depends on the geographical areas, as they influence agricultural, varietal, and seasonal practices, e.g., the fruit variety and maturity stage. ${ }^{46,49}$ Oleuropein is the most abundant compound present in Olea europaea L. leaves, ${ }^{51,52,54,55}$ followed by verbascoside and isoverbascoside, oleoside, hydroxytyrosol (3,4-dihydroxyphenolethanol; 3,4-DHPEA), luteolin-7-O-glucoside, and ligstroside, ${ }^{52}$ as well as apigenin-7-O-glucoside and luteolin- $4^{\prime}-O$ glucoside. $^{51}$ Studies were performed to characterize the phenolic profile of olive wastes (mill wastewaters and olive cake) from four different areas of a region in Morocco, ${ }^{48,49}$ concluding that the phenolic composition was different according to the geographical area, with hydroxytyrosol, tyrosol, $p$-coumaric acid, and hydroxytyrosol glucoside as the main compounds. El-Abbassi et al. $(2012)^{47}$ also reported hydroxytyrosol, gallic acid, and p-coumaric acid as the most abundant phenolic compounds in the olive mill wastewaters. Obied et al. $(2008)^{50}$ identified verbascoside as the most potent antioxidant present in Australian olive mill wastes, followed by 3,4-dihydroxyphenylethyl alcohol-deacetoxyelenolic acid dialdehyde (3,4-DHPEA-DEDA).

As mentioned above, the total phenolic content and composition recovered from the biomass also depend on the extraction procedure. The most interesting residue of the olive oil industry is the olive pomace, also known as olive cake. High amounts of oleuropein derivatives, such as elenolic acid (EA), the dialdehydic form of elenolic acid linked to hydroxytyrosol (3,4-DHPEA-EDA), oleuropein aglycone (3,4-DHPEA-EA), the dialdehydic form of elenolic acid linked to tyrosol ( $p$ HPEA-EDA), and hydroxytyrosol, were isolated from olive 
pomaces from the region of Les Garrigues (Catalonia, Spain). ${ }^{53}$ Cioffi et al. $(2010)^{45}$ studied the phenolic composition of virgin olive oil and olive oil pomace from the Campania region, in Italy, and found that oleuropein, oleuropein aglycone, ligstroside aglycone, hydroxytyrosol, tyrosol, and gallic acid are the most abundant phenolic compounds in both types of samples. More recently, Antónia Nunes et al. (2018) ${ }^{27}$ compared a multifrequency multimode modulated (MMM) ultrasonic technique with a conventional solid-liquid method for the extraction of phenolic compounds from olive pomace of the Trás-os-Montes region in Portugal. The MMM technique increased the concentration of the extracted antioxidant compounds in a shorter period of time. In this sample, the major compounds identified were hydroxytyrosol $>$ comselogoside $>$ elenolic acid derivative $>$ tyrosol > oleoside riboside.

Several fruits and vegetable wastes have also been reported to contain relevant amounts of phenolic compounds with high antioxidant potential. As examples, potato peel, ${ }^{56}$ fruit pee $^{57}$ and pulp, ${ }^{58}$ onionskin, ${ }^{59}$ and tomato processing wastes ${ }^{60}$ can be indicated. Gorinstein et al. $(2001)^{57}$ evaluated the antioxidant properties of some citrus fruit wastes, namely, Citrus limon (L.) Osbeck, Citrus sinensis (L.) Osbeck, and Citrus paradise Macfad. peels, reporting high contents of ferulic, sinapic, $p$-coumaric, caffeic, and ascorbic acids. Concerning onion wastes, Benitez et al. $(2011)^{59}$ observed that brown skin, outer and inner scales and top and bottom of Allium cepa L. were particularly rich in quercetin- $4^{\prime}-O$ glucoside and quercetin-3,4'-O-diglucoside. In Lycopersicon esculentum L. processing wastes, mainly consisting of skin and seeds, the major compounds detected were $p$-coumaric, caffeic, and chlorogenic acids as phenolic acids and chrysin and naringenin as flavonoids. ${ }^{60}$ Castro-Vargas et al. $(2019)^{61}$ explored the potential of the agro-industrial waste from two Colombian mango cultivars, "sugar mango" and "Tommy Atkins", as sources of bioactive phenolic compounds. The "sugar mango" kernel extracts presented the highest bioactive properties, with mangiferin and several galloyl glucosides as the most abundant compounds. Chlorogenic, gallic, vanillic, and protocatechuic acids were the major phenolic compounds found in Mangifera indica L. "Ataulfo" pulp, ${ }^{58}$ which tended to increase with fruit ripening and also their contribution for antioxidant activity. More recently, Coelho et al. (2019) ${ }^{62}$ demonstrated that mango peels could be used to produce liqueurs by alcoholic maceration. These liqueurs were revealed to have high antioxidant activity, and quantitatively, the main bioactive compounds found were flavanols (epicatechin gallate, epigallocatechin gallate), flavonols (quercetin-3-O-glucoside and rutin), and phenolic acids (gallic acid, $o$-coumaric acid, and syringic acid).

Wine production generates different wastes, such as stem, skin, and seeds ${ }^{63,64}$ and pomaces. ${ }^{65-68}$ Ribeiro et al. $(2015)^{67}$ reported the presence of high amounts of gallic, syringic, vanillic, and caffeic acids, quercetin, rutin, and catechin, in addition to anthocyanins, especially malvidin-3-O-glucoside, malvidin-3-O-acetylglucoside, and malvidin-3-O-p-coumaroylglucoside, in Vitis vinifera L. pomace. Doshi et al. $(2015)^{63}$ suggested that grape seeds, skin, and stem extracts not only have high antioxidant properties but also have the potential as insulin secretagogues, which might be useful in the treatment of type II diabetes. Gallic acid, catechin, and epicatechin were identified as major phenolic compounds in winery wastes, ${ }^{64}$ but hydroxytyrosol, tyrosol, cyanidin glycosides, and various phenolic acids, such as caffeic, syringic, vanillic, $p$-coumaric, and $o$-coumaric acids, were also found.

\section{IONIZING RADIATION TECHNOLOGIES}

Radiation technologies offer versatile tools that play an important role in supporting sustainable development. ${ }^{69}$ Ionizing radiation does not require the addition of chemicals or heat to induce changes in the matter, having a much lower carbon footprint than other technologies. In this way, it is more cost-effective and environmentally friendly than traditional alternatives, requiring less energy and generating less waste. $^{70}$

There are different sources of ionizing radiation used in different sectors of industry and agriculture: ${ }^{71,72} \gamma$-radiation, that is constituted by photons produced from radioactive isotopes cobalt-60 $\left({ }^{60} \mathrm{Co}\right)$ and cesium-137 $\left({ }^{137} \mathrm{Cs}\right)$, and accelerators, capable of producing electron beams and X-rays. Radioisotopes are useful due to their permanent source, high efficiency associated with their penetrating power and their easy replacement. Electron-beam accelerators do not rely on a radioactive source and present the advantage that they are able to be switched on and off depending on the necessity.

Radiation technologies are safe processes becoming part of the solution for many countries to develop new tools and approaches in different areas, ranging from health and the environment to industry and infrastructure. ${ }^{69}$

5.1. Radiation Processing. Ionizing radiation is currently used for different applications: medical device sterilization, ${ }^{73}$ material modification, ${ }^{74}$ heritage preservation, ${ }^{75}$ or wastewater treatment, ${ }^{76}$ among others. Contrarily to ethylene oxide treatment that can leave toxic residues on treated products, ionizing radiation can be safely used to sterilize healthcare products such as syringes, surgical gloves, or tissue allografts in sealed packages, in order to reduce the microbiological contamination to acceptable levels. ${ }^{77}$ This technology can also be applied on the preparation and functionalization of hybrid materials that are used for biomedical applications and food packaging. ${ }^{74}$ On the other hand, Borrely et al. $(2016)^{76}$ demonstrated that electron-beam radiation was capable of reducing the color $(>90 \%$ at $2.5 \mathrm{kGy})$ and toxicity of three different textile effluents and Madureira et al. ${ }^{78}$ showed the radiolytic degradation of phenolic acids present in wastewaters from the cork industry. In addition, $\gamma$-radiation was used to decontaminate and preserve parchment documents as an alternative to the chemical (e.g., fumigants) and nonchemical (e.g., modified indoor atmospheres) treatments that induce toxicity and deterioration of the documents. ${ }^{75}$

Both types of irradiation have also been used for food processing and have shown to be effective in reducing pathogenic bacteria, eliminating parasites, decreasing postharvest sprouting, and extending the shelf life of fresh perishable food. ${ }^{70}$ Furthermore, irradiation can also be applied to enhance extraction or improve the bioactive properties of some of the chemical compounds present in food, wastes, and plants. In the present review, we will focus on the extractability and bioactive properties of agro-industrial residues.

5.2. Ionizing Radiation in Agro-Industrial Residues: Enhancement of Phenolic Compounds Extractability and Bioactive Properties. Although there is no ideal method for extracting bioactive compounds, ionizing radiation technologies have proven to improve the extraction yield and bioactive properties of agro-industrial residues. In recent years, several studies have been published regarding the extractability 


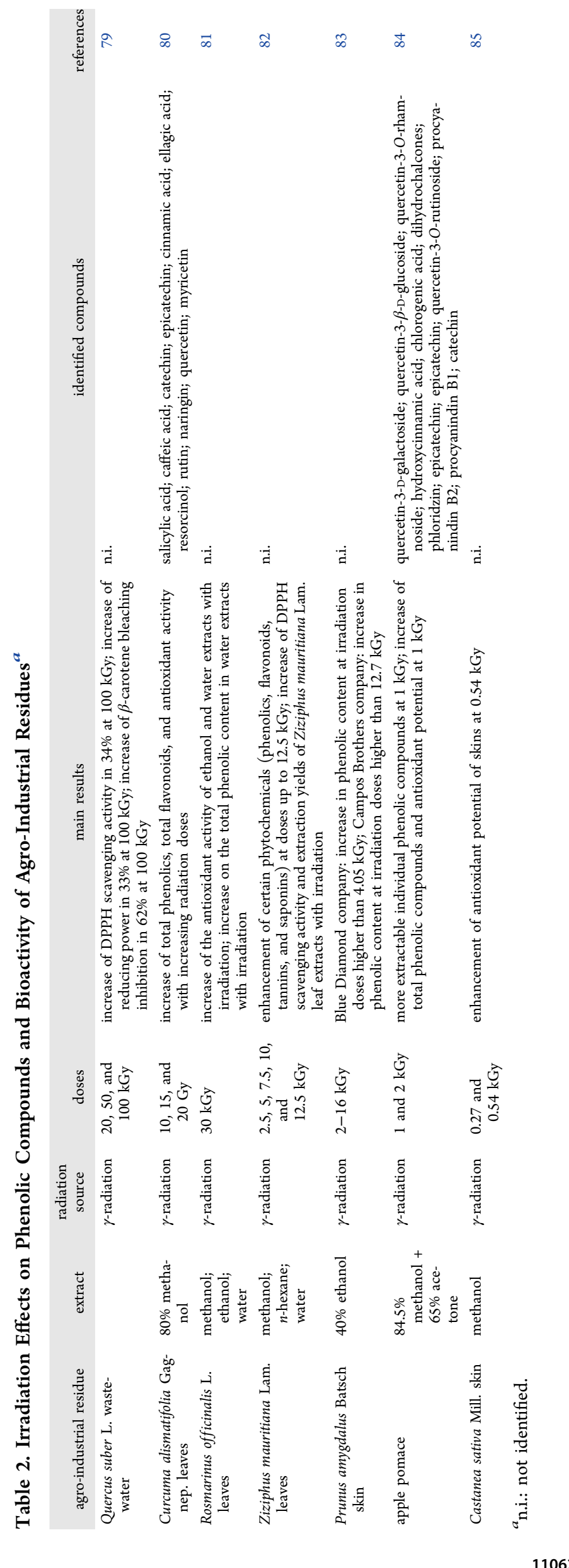


and bioactive properties improvement of chemical compounds from irradiated food and agro-wastes, demonstrating the high potentiality of this treatment (Table 2).

A study developed by Madureira et al. $(2017)^{79}$ revealed that $\gamma$-radiation at $100 \mathrm{kGy}$ was capable of improving (34$62 \%)$ the antioxidant activity of wastewaters generated during Q. suber L. processing. Taheri, Abdullah, Karimi, Oskoueian, and Ebrahimi $(2014)^{80}$ demonstrated that $20 \mathrm{~Gy}$ of $\gamma$-radiation was enough to significantly increase the total phenolics (2fold) and total flavonoids (2-fold) contents in Curcuma alismatifolia Gagnep. leaves compared to the nonirradiated ones. An increase of $35 \%$ on total phenolic content was observed in water extracts of Rosmarinus officinalis L. leaves irradiated at $30 \mathrm{kGy}$ but not in methanol or ethanol extracts. ${ }^{81}$ The authors associated this increase with the presence of diterpenes in rosemary that could result in water-soluble quinone-type compounds by $\gamma$-radiation. For their part, Khattak and Rahman $(2016)^{82}$ showed that $\gamma$-radiation doses up to $12.5 \mathrm{kGy}$ enhanced the levels of certain phytochemicals (phenolic acids, flavonoids, tannins, and saponins) and increased the DPPH scavenging activity and extraction yield of Ziziphus mauritiana Lam. leaves extracts.

Harrison and Were $(2007)^{83}$ reported two different irradiation levels causing the enhancement of the total phenolic content and antioxidant activity of Prunus amygdalus Batsch. skin extracts, although dependent on the almond skin origin. Almond skins supplied by the company Blue Diamond Growers showed an increase in phenolic content at irradiation doses higher than $4.05 \mathrm{kGy}$ (about $45 \%$ compared to the control), while almond skins from Campos Brothers showed an increase in phenolic content at irradiation doses higher than 12.7 kGy (about 20\% compared to the control).

Apple pomace is another interesting source of phenolic compounds. Irradiation of apple pomace flour at $1 \mathrm{kGy}$ enhanced the extractability of individual and total phenolic compounds, as well as the antioxidant potential. ${ }^{84}$ More specifically, total phenolic compounds increased from $563 \pm$ $50 \mathrm{mg} / 100 \mathrm{~g}(0 \mathrm{kGy})$ to $661 \pm 33 \mathrm{mg} / 100 \mathrm{~g}$ (1 kGy) and antioxidant capacity by FRAP assay increased more than $50 \%$ (from $36.19 \pm 1.36$ to $57 \pm 1 \mathrm{mmol}$ trolox equivalents/g for nonirradiated and irradiated at $1 \mathrm{kGy}$ sample, respectively).

Chestnuts are also another important source of polyphenols with antioxidant potential. António et al. $(2011)^{85}$ reported an increase of the antioxidant capacity in Castanea sativa Mill. skins irradiated at $0.54 \mathrm{kGy}$ of $64 \%$ evaluated by the $\beta$-carotene bleaching inhibition assay.

5.3. Radiation Chemistry. The effect of ionizing radiation on extraction yields can vary depending on the compounds that constitute the studied matrixes. The increase in total phenolic and flavonoid contents on irradiated samples could be due to the release of these compounds from matrix structures, increasing the extractability of certain molecules, or the degradation of larger compounds (e.g., tannins) into smaller ones by the radiolytic action of ionizing radiation. ${ }^{86}$ The higher extractability can be explained by changes in cellular structures, namely, by the depolymerization and dissolution of the cell wall polysaccharides by irradiation. ${ }^{83,87,88}$ Moreover, irradiation is recognized as promoting the activity of phenylalanine ammonia-lyase, responsible for the synthesis of phenolic compounds, ${ }^{89}$ and, consequently, the enhancement of antioxidant activity.
In addition, as mentioned above, the increase or decrease on the antioxidants is strongly dependent on the solvents used for the extraction. ${ }^{81,82,90}$

\section{APPLICATIONS OF BIOACTIVE COMPOUNDS EXTRACTED FROM AGRO-INDUSTRIAL RESIDUES}

With the growing interest of consumers toward food bioactives that provide beneficial effects on human health promotion and disease risk reduction, the extracts from irradiated residues with improved properties can be incorporated in food products and contribute for the development of functional foods. Different investigations have focused on the development of functional foods through fortification, which consists of incorporating one or more bioactive compounds in order to correct or improve a potential biological activity of the food product. There are several studies concerning the incorporation of bioactive compounds from agro-industrial residues into different dietary matrixes of high importance, namely, bread, pastry, biscuits, and yogurt. ${ }^{91-94}$ Myrciaria dubia (Kunth) McVaugh peel was used to fortify yogurt, ${ }^{91}$ resulting in an enhancement in bioactive components in the new product without significantly altering its nutritional composition and fatty acid profile. Punica granatum L. epicarp extracts were incorporated in a typical Brazilian pastry product. ${ }^{92}$ The new formulations showed greater antioxidant activity that remained unchanged during the 14 days of storage. At the same time, the cake prepared by new formulations presented a rose color and a soft texture, which can also be important factors for the consumer acceptance. Also, Hallabo et al. ${ }^{93}$ substituted wheat flour of biscuits by $6 \%$ peel powders of $M$. indica L. cv. Copania, A. cepa, and Solanum tuberosum L. The obtained results demonstrated that the new prepared biscuits had higher antioxidant activity, total carotenoids, and total polyphenols than the control ones. In another study performed by Mildner-Szkudlarz et al., ${ }^{94}$ a new formulation for sourdough mixed rye bread was produced incorporating a maximum of $6 \%$ grape byproducts and presented an improvement in antioxidant activity due to the higher values of phenolic compounds.

There are a few patents on the application of agro-industrial residues on food products. ${ }^{95}$ For example, a straightforward method for obtaining polyphenol extracts from white grape residues to having antioxidant and antibacterial properties was patented to be used on an industrial scale in the cosmetic, pharmaceutical, and/or food industries. ${ }^{96,97}$ Another process that utilizes cheese/yogurt whey and fruit pomace to directly yield extruded, ready-to-eat products such as breakfast cereals, healthy snacks, protein puffs, and nutrition bars, among other food items, was also patented. ${ }^{98}$

The actual trend is the bioactive compounds production by extraction from residual food sources, ${ }^{95}$ although further research on the irradiation of different agro-industrial residues should be performed to increase its applicability and to valorize the wastes by enhancing their health benefits and maintain environmental sustainability.

\section{AUTHOR INFORMATION}

\section{Corresponding Authors}

Sandra Cabo Verde - Centro de Cîncias e Tecnologias Nucleares (C2TN), Instituto Superior Técnico, Universidade de Lisboa, 2695-066 Bobadela LRS, Portugal; @ orcid.org/00000002-6615-5289; Email: sandracv@ctn.tecnico.ulisboa.pt 
Isabel C. F. R. Ferreira - Centro de Investigação de Montanha (CIMO), Instituto Politéenico de Bragança, 5300-253

Bragança, Portugal; Email: iferreira@ipb.pt

\section{Authors}

Joana Madureira - Centro de Cîncias e Tecnologias Nucleares (C2TN), Instituto Superior Técnico, Universidade de Lisboa, 2695-066 Bobadela LRS, Portugal; Centro de Investigação de Montanha (CIMO), Instituto Politécnico de Bragança, 5300253 Bragança, Portugal; Grupo de Investigación en Polifenoles (GIP-USAL), Facultad de Farmacia, Universidad de Salamanca, 37007 Salamanca, Spain

Lillian Barros - Centro de Investigação de Montanha (CIMO), Instituto Politécnico de Bragança, 5300-253 Bragança, Portugal

Fernanda M. A. Margaça - Centro de Cîencias e Tecnologias Nucleares (C2TN), Instituto Superior Técnico, Universidade de Lisboa, 2695-066 Bobadela LRS, Portugal

Celestino Santos-Buelga - Grupo de Investigación en Polifenoles (GIP-USAL), Facultad de Farmacia, Universidad de Salamanca, 37007 Salamanca, Spain

Complete contact information is available at: https://pubs.acs.org/10.1021/acs.jafc.0c04984

\section{Notes}

The authors declare no competing financial interest.

\section{ACKNOWLEDGMENTS}

The authors are grateful to the Foundation for Science and Technology (FCT, Portugal) for financial support to $\mathrm{C}^{2} \mathrm{TN}$ (UIDB/04349/2020), CIMO (UIDB/00690/2020), and J.M. (SFRH/BD/136506/2018); L.B. thanks FCT for the national funding, P.I., through the institutional scientific employment program-contract; FEDER-Interreg España-Portugal programme for financial support through the project 0377 Iberphenol_6_E.

\section{REFERENCES}

(1) Sadh, P. K.; Duhan, S.; Duhan, J. S. Agro-Industrial Wastes and Their Utilization Using Solid State Fermentation: A Review. Bioresour. Bioprocess. 2018, 5 (1), 1-15.

(2) Bharat Helkar, P.; Sahoo, A.; Patil, N. J. Review: Food Industry By-Products Used as a Functional Food Ingredients. Int. J. Wastes Resour. 2016, 6 (3), 1-6. DOI: 10.4172/2252-5211.1000248.

(3) Yusuf, M. Agro-Industrial Waste Materials and Their Recycled Value-Added Applications: Review. In Handbook of Ecomaterials; Martínez, L. M. T., Kharissova, O. V., Ildusovich Kharisov, B., Eds.; Springer: 2017. DOI: 10.1007/978-3-319-48281-1.

(4) Carocho, M.; Morales, P.; Ferreira, I. C. F. R. Natural Food Additives: Quo Vadis? Trends Food Sci. Technol. 2015, 45, 284-295.

(5) Faustino, M.; Veiga, M.; Sousa, P.; Costa, E. M.; Silva, S.; Pintado, M. Agro-Food Byproducts as a New Source of Natural Food Additives. Molecules 2019, 24 (6), 1056.

(6) Shirahigue, L. D.; Ceccato-Antonini, S. R. Agro-Industrial Wastes as Sources of Bioactive Compounds for Food and Fermentation Industries. Cienc. Rural 2020, 50 (4), No. e20190857.

(7) Vuong, Q. V. Utilisation of Bioactive Compounds from Agricultural and Food Waste; CRC Press: Boca Raton, FL, 2017. DOI: 10.1201/ 9781315151540.

(8) Azeez, S.; Narayana, C. K.; Oberoi, H. S. Extraction and Utilisation of Bioactive Compounds from Agricultural Waste. In Utilisation of Bioactive Compounds from Agricultural and Food Waste; Vuong, Q. V., Ed.; Taylor \& Francis: Boca Raton, 2017.

(9) Santana-Méridas, O.; González-Coloma, A.; Sánchez-Vioque, R. Agricultural Residues as a Source of Bioactive Natural Products. Phytochem. Rev. 2012, 11 (4), 447-466.
(10) Selvamuthukumaran, M.; Shi, J. Recent Advances in Extraction of Antioxidants from Plant By-Products Processing Industries. Food Qual. Saf. 2017, 1 (1), 61-81.

(11) Fierascu, R. C.; Fierascu, I.; Avramescu, S. M.; Sieniawska, E. Recovery of Natural Antioxidants from Agro-Industrial Side Streams through Advanced Extraction Techniques. Molecules 2019, 24, 4212.

(12) Ghafoor, K.; Hui, T.; Choi, Y. H. Optimization of UltrasonicAssisted Extraction of Total Anthocyanins from Grape Peel Using Response Surface Methodology. J. Food Biochem. 2011, 35, 735-746.

(13) Altemimi, A.; Watson, D. G.; Choudhary, R.; Dasari, M. R.; Lightfoot, D. A. Ultrasound Assisted Extraction of Phenolic Compounds from Peaches and Pumpkins. PLoS One 2016, 11 (2), e0148758.

(14) Bouras, M.; Grimi, N.; Bals, O.; Vorobiev, E. Impact of Pulsed Electric Fields on Polyphenols Extraction from Norway Spruce Bark. Ind. Crops Prod. 2016, 80, 50-58.

(15) Boussetta, N.; Grimi, N.; Vorobiev, E. Pulsed Electrical Technologies Assisted Polyphenols Extraction from Agricultural Plants and Bioresources: A Review. Int. J. Food Process. Technol. 2015, 2 (1), 1-10.

(16) Mushtaq, M.; Sultana, B.; Bhatti, H. N.; Asghar, M. RSM Based Optimized Enzyme-Assisted Extraction of Antioxidant Phenolics from Underutilized Watermelon (Citrullus Lanatus Thunb.) Rind. J. Food Sci. Technol. 2015, 52 (8), 5048-5056.

(17) Gómez-García, R.; Martínez-Ávila, G. C. G.; Aguilar, C. N. Enzyme-Assisted Extraction of Antioxidative Phenolics from Grape (Vitis Vinifera L.) Residues. 3 Biotech 2012, 2 (4), 297-300.

(18) Ranveer, R. C.; Patil, S. N.; Sahoo, A. K. Effect of Different Parameters on Enzyme-Assisted Extraction of Lycopene from Tomato Processing Waste. Food Bioprod. Process. 2013, 91 (4), 370-375.

(19) Thirugnanasambandham, K.; Sivakumar, V. Microwave Assisted Extraction Process of Betalain from Dragon Fruit and Its Antioxidant Activities. J. Saudi Soc. Agric. Sci. 2017, 16 (1), 41-48.

(20) Pavlić, B.; Naffati, A.; Hojan, T.; Vladić, J.; Zeković, Z.; Vidović, S. Microwave-Assisted Extraction of Wild Apple Fruit DustProduction of Polyphenol-Rich Extracts from Filter Tea Factory byProducts. J. Food Process Eng. 2017, 40 (4), e12508.

(21) Shang, Y.-F.; Hyun Cha, K.; Ha Lee, E.; Pan, C.-H.; Um, B.-H. Optimization, Bio Accessibility of Tricin and Anti-Oxidative Activity of Extract from Black Bamboo Leaves. Free Radicals Antioxid. 2016, 6 (1), 64-71.

(22) Farías-Campomanes, A. M.; Rostagno, M. A.; Coaquira-Quispe, J. J.; Meireles, M. A. A. Supercritical Fluid Extraction of Polyphenols from Lees: Overall Extraction Curve, Kinetic Data and Composition of the Extracts. Bioresour. Bioprocess 2015, 2, 45.

(23) M'hiri, N.; Ioannou, I.; Paris, C.; Ghoul, M.; Boudhrioua, N. Comparison of the Efficiency of Different Extraction Methods on Antioxidants of Maltease Orange Peel. Int. J. Food Nutr. Sci. 2016, 3 (2), $1-13$.

(24) Tabaraki, R.; Ghadiri, F. Comparative Study of Extraction Methods for Pistachio Hull Antioxidants by Multiple Assays. J. Appl. Chem. 2016, 10 (37), 19-30.

(25) Vieira, V.; Prieto, M. A.; Barros, L.; Coutinho, J. A. P.; Ferreira, O.; Ferreira, I. C. F. R. Optimization and Comparison of Maceration and Microwave Extraction Systems for the Production of Phenolic Compounds from Juglans Regia L. for the Valorization of Walnut Leaves. Ind. Crops Prod. 2017, 107, 341-352.

(26) Backes, E.; Pereira, C.; Barros, L.; Prieto, M. A.; Genena, A. K.; Barreiro, M. F.; Ferreira, I. C. F. R. Recovery of Bioactive Anthocyanin Pigments from Ficus Carica L. Peel by Heat, Microwave, and Ultrasound Based Extraction Techniques. Food Res. Int. 2018, 113, 197-209.

(27) Antónia Nunes, M.; Costa, A. S. G.; Bessada, S.; Santos, J.; Puga, H.; Alves, R. C.; Freitas, V.; Oliveira, M. B. P. P. Olive Pomace as a Valuable Source of Bioactive Compounds: A Study Regarding Its Lipid- and Water-Soluble Components. Sci. Total Environ. 2018, 644, 229-236. 
(28) Zhang, Q. W.; Lin, L. G.; Ye, W. C. Techniques for Extraction and Isolation of Natural Products: A Comprehensive Review. Chin. Med. (London, U. K.) 2018, 13, 20.

(29) Brusotti, G.; Cesari, I.; Dentamaro, A.; Caccialanza, G.; Massolini, G. Isolation and Characterization of Bioactive Compounds from Plant Resources: The Role of Analysis in the Ethnopharmacological Approach. J. Pharm. Biomed. Anal. 2014, 87, 218.

(30) Fierascu, R. C.; Fierascu, I.; Avramescu, S. M.; Sieniawska, E. Recovery of Natural Antioxidants from Agro-Industrial Side Streams through Advanced Extraction Techniques. Molecules 2019, 24 (23), 4212.

(31) Sasidharan, S.; Chen, Y.; Saravanan, D.; Sundram, K. M.; Latha, L. Y. Extraction, Isolation and Characterization of Bioactive Compounds from Plants' Extracts. Afr. J. Tradit., Complementary Altern. Med. 2010, 8 (1), 1-10.

(32) Castro-Vazquez, L.; Alañón, M. E.; Rodríguez-Robledo, V.; Pérez-Coello, M. S.; Hermosín-Gutierrez, I.; Díaz-Maroto, M. C.; Jordán, J.; Galindo, M. F.; Arroyo-Jiménez, M. D. M. Bioactive Flavonoids, Antioxidant Behaviour, and Cytoprotective Effects of Dried Grapefruit Peels (Citrus Paradisi Macf.). Oxid. Med. Cell. Longevity 2016, 2016, 8915729.

(33) Babbar, N.; Oberoi, H. S.; Sandhu, S. K. Therapeutic and Nutraceutical Potential of Bioactive Compounds Extracted from Fruit Residues. Crit. Rev. Food Sci. Nutr. 2015, 55 (3), 319-337.

(34) Farah, A.; Donangelo, C. M. Phenolic Compounds in Coffee. Braz. J. Plant Physiol. 2006, 18 (1), 23-36.

(35) Huang, Y. P.; Lai, H. M. Bioactive Compounds and Antioxidative Activity of Colored Rice Bran. J. Food Drug Anal. 2016, 24 (3), 564-574.

(36) López-Perea, P.; Guzmán-Ortiz, F. A.; Román-Gutiérrez, A. D.; Castro-Rosas, J.; Gómez-Aldapa, C. A.; Rodríguez-Marín, M. L.; Falfán-Cortés, R. N.; González-Olivares, L. G.; Torruco-Uco, J. G. Bioactive Compounds and Antioxidant Activity of Wheat Bran and Barley Husk in the Extracts with Different Polarity. Int. J. Food Prop. 2019, 22 (1), 646-658.

(37) Vijayalaxmi, S.; Jayalakshmi, S. K.; Sreeramulu, K. Polyphenols from Different Agricultural Residues: Extraction, Identification and Their Antioxidant Properties. J. Food Sci. Technol. 2015, 52 (5), 2761-2769.

(38) Santos, S. A. O.; Pinto, P. C. R. O.; Silvestre, A. J. D.; Neto, C. P. Chemical Composition and Antioxidant Activity of Phenolic Extracts of Cork from Quercus Suber L. Ind. Crops Prod. 2010, 31 (3), 521-526.

(39) Santos, S. A. O.; Freire, C. S. R.; Domingues, M. R. M.; Silvestre, A. J. D.; Neto, C. P. Characterization of Phenolic Components in Polar Extracts of Eucalyptus Globulus Labill. Bark by High-Performance Liquid Chromatography-Mass Spectrometry. J. Agric. Food Chem. 2011, 59 (17), 9386-9393.

(40) Santos, S. A. O.; Villaverde, J. J.; Silva, C. M.; Neto, C. P.; Silvestre, A. J. D. Supercritical Fluid Extraction of Phenolic Compounds from Eucalyptus Globulus Labill Bark. J. Supercrit. Fluids 2012, 71, 71-79.

(41) Santos, S. A. O.; Villaverde, J. J.; Freire, C. S. R.; Domingues, R. M. M.; Neto, C. P.; Silvestre, A. J. D. Phenolic Composition and Antioxidant Activity of Eucalyptus Grandis, E. Urograndis (E. Grandis $\times$ E. Urophylla) and E. Maidenii Bark Extracts. Ind. Crops Prod. 2012, 39 (1), 120-127.

(42) Minhalma, M.; De Pinho, M. N. Tannic-Membrane Interactions on Ultrafiltration of Cork Processing Wastewaters. Sep. Purif. Technol. 2001, 22-23, 479-488.

(43) Valadez-Carmona, L.; Plazola-Jacinto, C. P.; HernándezOrtega, M.; Hernández-Navarro, M. D.; Villarreal, F.; NecoecheaMondragón, H.; Ortiz-Moreno, A.; Ceballos-Reyes, G. Effects of Microwaves, Hot Air and Freeze-Drying on the Phenolic Compounds, Antioxidant Capacity, Enzyme Activity and Microstructure of Cacao Pod Husks (Theobroma Cacao L.). Innovative Food Sci. Emerging Technol. 2017, 41, 378-386.

(44) Abdul Karim, A.; Azlan, A.; Ismail, A.; Hashim, P.; Abd Gani, S. S.; Zainudin, B. H.; Abdullah, N. A. Phenolic Composition,
Antioxidant, Anti-Wrinkles and Tyrosinase Inhibitory Activities of Cocoa Pod Extract. BMC Complementary Altern. Med. 2014, 14 (381), 381.

(45) Cioffi, G.; Pesca, M. S.; De Caprariis, P.; Braca, A.; Severino, L.; De Tommasi, N. Phenolic Compounds in Olive Oil and Olive Pomace from Cilento (Campania, Italy) and Their Antioxidant Activity. Food Chem. 2010, 121 (1), 105-111.

(46) Yakhlef, W.; Arhab, R.; Romero, C.; Brenes, M.; de Castro, A.; Medina, E. Phenolic Composition and Antimicrobial Activity of Algerian Olive Products and By-Products. LWT - Food Sci. Technol. 2018, 93 (March), 323-328.

(47) El-Abbassi, A.; Kiai, H.; Hafidi, A. Phenolic Profile and Antioxidant Activities of Olive Mill Wastewater. Food Chem. 2012, 132 (1), 406-412.

(48) Leouifoudi, I.; Mbarki, M.; Tilaoui, M.; Amechrouq, A.; Mostapha, E.; Mouse, H. A.; Zyad, A. Study of the in Vitro Anticancer Activity of Moroccan Phenolic Olive Cake Extracts. J. Pharmacogn. Phytochem. 2014, 2 (March), 154-165.

(49) Leouifoudi, I.; Zyad, A.; Amechrouq, A.; Oukerrou, M. A.; Mouse, H. A.; Mbarki, M. Identification and Characterisation of Phenolic Compounds Extracted from Moroccan Olive Mill Wastewater. Food Sci. Technol. 2014, 34 (2), 249-257.

(50) Obied, H. K.; Prenzler, P. D.; Robards, K.; Graham, E. H. Potent Antioxidant Biophenols from Olive Mill Waste. Food Chem. 2008, 111, 171-178.

(51) Pereira, A. P.; Ferreira, I. C.; Marcelino, F.; Valentão, P.; Andrade, P. B.; Seabra, R.; Estevinho, L.; Bento, A.; Pereira, J. A. Phenolic Compounds and Antimicrobial Activity of Olive (Olea Europaea L. Cv. Cobrançosa) Leaves. Molecules 2007, 12 (5), $1153-$ 1162.

(52) Quirantes-Piné, R.; Lozano-Sánchez, J.; Herrero, M.; Ibáñez, E.; Segura-Carretero, A.; Fernández-Gutiérrez, A. HPLC-ESI-QTOF-MS as a Powerful Analytical Tool for Characterising Phenolic Compounds in Olive-Leaf Extracts. Phytochem. Anal. 2013, 24 (3), 213-223.

(53) Suárez, M.; Romero, M.-P.; Ramo, T.; Macià, A.; Motilva, M.-J. Methods for Preparing Phenolic Extracts from Olive Cake for Potential Application as Food Antioxidants. J. Agric. Food Chem. 2009, 57, 1463-1472.

(54) Talhaoui, N.; Gómez-Caravaca, A. M.; León, L.; De la Rosa, R.; Segura-Carretero, A.; Fernández-Gutiérrez, A. Determination of Phenolic Compounds of "Sikitita" Olive Leaves by HPLC-DADTOF-MS. Comparison with Its Parents "Arbequina" and "Picual" Olive Leaves. LWT - Food Sci. Technol. 2014, 58 (1), 28-34.

(55) Quirantes-Piné, R.; Zurek, G.; Barrajón-Catalán, E.; Bäßmann, C.; Micol, V.; Segura-Carretero, A.; Fernández-Gutiérrez, A. A Metabolite-Profiling Approach to Assess the Uptake and Metabolism of Phenolic Compounds from Olive Leaves in SKBR3 Cells by HPLC-ESI-QTOF-MS. J. Pharm. Biomed. Anal. 2013, 72, 121-126.

(56) Mattila, P.; Hellström, J. Phenolic Acids in Potatoes, Vegetables, and Some of Their Products. J. Food Compos. Anal. 2007, 20 (3-4), 152-160.

(57) Gorinstein, S.; Martín-Belloso, O.; Park, Y. S.; Haruenkit, R.; Lojek, A.; Íž, M.; Caspi, A.; Libman, I.; Trakhtenberg, S. Comparison of Some Biochemical Characteristics of Different Citrus Fruits. Food Chem. 2001, 74 (3), 309-315.

(58) Palafox-Carlos, H.; Yahia, E. M.; González-Aguilar, G. A. Identification and Quantification of Major Phenolic Compounds from Mango (Mangifera Indica, Cv. Ataulfo) Fruit by HPLC-DAD-MS/ MS-ESI and Their Individual Contribution to the Antioxidant Activity during Ripening. Food Chem. 2012, 135 (1), 105-111.

(59) Benítez, V.; Mollá, E.; Martín-Cabrejas, M. A.; Aguilera, Y.; López-Andréu, F. J.; Cools, K.; Terry, L. A.; Esteban, R. M. Characterization of Industrial Onion Wastes (Allium Cepa L.): Dietary Fibre and Bioactive Compounds. Plant Foods Hum. Nutr. 2011, 66 (1), 48-57.

(60) Kalogeropoulos, N.; Chiou, A.; Pyriochou, V.; Peristeraki, A.; Karathanos, V. T. Bioactive Phytochemicals in Industrial Tomatoes 
and Their Processing Byproducts. LWT - Food Sci. Technol. 2012, 49 (2), 213-216.

(61) Castro-Vargas, H.; Ballesteros Vivas, D.; Ortega Barbosa, J.; Morantes Medina, S.; Aristizabal Gutierrez, F.; Parada-Alfonso, F. Bioactive Phenolic Compounds from the Agroindustrial Waste of Colombian Mango Cultivars 'Sugar Mango' and 'Tommy Atkins'An Alternative for Their Use and Valorization. Antioxidants 2019, 8 (2), 41.

(62) Coelho, E. M.; de Souza, M. E. A. O.; Corrêa, L. C.; Viana, A. C.; De Azevêdo, L. C.; Lima, M. D. S. Bioactive Compounds and Antioxidant Activity of Mango Peel Liqueurs (Mangifera Indica L.) Produced by Different Methods of Maceration. Antioxidants 2019, 8 (4), $1-11$.

(63) Doshi, P.; Adsule, P.; Banerjee, K.; Oulkar, D. Phenolic Compounds, Antioxidant Activity and Insulinotropic Effect of Extracts Prepared from Grape (Vitis Vinifera L) Byproducts. J. Food Sci. Technol. 2015, 51 (1), 181-190.

(64) Lafka, T. I.; Sinanoglou, V.; Lazos, E. S. On the Extraction and Antioxidant Activity of Phenolic Compounds from Winery Wastes. Food Chem. 2007, 104 (3), 1206-1214.

(65) Iora, S. R. F.; Maciel, G. M.; Zielinski, A. A. F.; da Silva, M. V.; Pontes, P. V. d. A.; Haminiuk, C. W. I.; Granato, D. Evaluation of the Bioactive Compounds and the Antioxidant Capacity of Grape Pomace. Int. J. Food Sci. Technol. 2015, 50 (1), 62-69.

(66) Peixoto, C. M.; Dias, M. I.; Alves, M. J.; Calhelha, R. C.; Barros, L.; Pinho, S. P.; Ferreira, I. C. F. R. Grape Pomace as a Source of Phenolic Compounds and Diverse Bioactive Properties. Food Chem. 2018, 253, 132-138.

(67) Ribeiro, L. F.; Ribani, R. H.; Francisco, T. M. G.; Soares, A. A.; Pontarolo, R.; Haminiuk, C. W. I. Profile of Bioactive Compounds from Grape Pomace (Vitis Vinifera and Vitis Labrusca) by Spectrophotometric, Chromatographic and Spectral Analyses. J. Chromatogr. B: Anal. Technol. Biomed. Life Sci. 2015, 1007, 72-80.

(68) Ramirez-Lopez, L. M.; DeWitt, C. A. M. Analysis of Phenolic Compounds in Commercial Dried Grape Pomace by High-Performance Liquid Chromatography Electrospray Ionization Mass Spectrometry. Food Sci. Nutr. 2014, 2 (5), 470-477.

(69) Amano, Y. Radiation Technology for a More Prosperous and Sustainable Future. IAEA Bull. 2017, 58 (1), 1.

(70) Food Irradiation Technologies: Concepts, Applications and Outcomes; Ferreira, I. C. F. R., Antonio, A. L., Cabo Verde, S., Eds.; Royal Society of Chemistry: 2018.

(71) Chernyaev, A. P.; Varzar, S. M.; Belousov, A. V.; Zheltonozhskaya, M. V.; Lykova, E. N. Prospects of Development of Radiation Technologies in Russia. Phys. At. Nucl. 2019, 82 (5), 513-527.

(72) Chmielewski, A. G.; Haji-Saeid, M. Radiation Technologies: Past, Present and Future. Radiat. Phys. Chem. 2004, 71 (1-2), 17-21.

(73) Buchalla, R.; Schüttler, C.; Bögl, K. W. Radiation Sterilization of Medical Devices. Effects of Ionizing Radiation on Ultra-High Molecular-Weight Polyethylene. Radiat. Phys. Chem. 1995, 46 (4-6), 579-585.

(74) Lancastre, J. J. H.; Falcão, A. N.; Margaça, F. M. A.; Ferreira, L. M.; Miranda Salvado, I. M.; Casimiro, M. H.; Almásy, L.; Meiszterics, A. Influence of the Polymer Molecular Weight on the Microstructure of Hybrid Materials Prepared by $\gamma$-Irradiation. Radiat. Phys. Chem. 2015, 106, 126-129.

(75) Nunes, I.; Mesquita, N.; Cabo Verde, S.; Carolino, M. M.; Portugal, A.; Botelho, M. L. Bioburden Assessment and Gamma Radiation Inactivation Patterns in Parchment Documents. Radiat. Phys. Chem. 2013, 88, 82-89.

(76) Borrely, S. I.; Morais, A. V.; Rosa, J. M.; Badaró-pedroso, C.; Pereira, C.; Higa, M. C. Decoloration and Detoxification of Effluents by Ionizing Radiation. Radiat. Phys. Chem. 2016, 124, 198-202.

(77) Parsons, B. J. Sterilisation of Healthcare Products by Ionising Radiation: Principles and Standards. Sterilisation of Biomaterials and Medical Devices; Woodhead Publishing Limited: 2012; pp 56-70. DOI: $10.1533 / 9780857096265.56$.
(78) Madureira, J.; Barros, L.; Melo, R.; Cabo Verde, S.; Ferreira, I. C. F. R.; Margaça, F. M. A. Degradation of Phenolic Acids by Gamma Radiation as Model Compounds of Cork Wastewaters. Chem. Eng. J. 2018, 341, 227-237.

(79) Madureira, J.; Pimenta, A. I.; Popescu, L.; Besleaga, A.; Dias, M. I.; Santos, P. M. P.; Melo, R.; Ferreira, I. C. F. R.; Cabo Verde, S.; Margaça, F. M. A. Effects of Gamma Radiation on Cork Wastewater: Antioxidant Activity and Toxicity. Chemosphere 2017, 169, 139-145.

(80) Taheri, S.; Abdullah, T. L.; Karimi, E.; Oskoueian, E.; Ebrahimi, M. Antioxidant Capacities and Total Phenolic Contents Enhancement with Acute Gamma Irradiation in Curcuma Alismatifolia (Zingiberaceae) Leaves. Int. J. Mol. Sci. 2014, 15 (7), 13077-13090.

(81) Pérez, M. B.; Calderón, N. L.; Croci, C. A. Radiation-Induced Enhancement of Antioxidant Activity in Extracts of Rosemary (Rosmarinus Officinalis L.). Food Chem. 2007, 104 (2), 585-592.

(82) Khattak, K. F.; Rahman, T. U. Effect of Gamma Irradiation on the Vitamins, Phytochemicals, Antimicrobial and Antioxidant Properties of Ziziphus Mauritiana Lam. Leaves. Radiat. Phys. Chem. 2016, $127,243-248$.

(83) Harrison, K.; Were, L. M. Effect of Gamma Irradiation on Total Phenolic Content Yield and Antioxidant Capacity of Almond Skin Extracts. Food Chem. 2007, 102 (3), 932-937.

(84) Ito, V. C.; Alberti, A.; Avila, S.; Spoto, M.; Nogueira, A.; Wosiacki, G. Effects of Gamma Radiation on the Phenolic Compounds and in Vitro Antioxidant Activity of Apple Pomace Flour during Storage Using Multivariate Statistical Techniques. Innovative Food Sci. Emerging Technol. 2016, 33, 251-259.

(85) António, A. L.; Fernandes, Â.; Barreira, J. C. M.; Bento, A.; Botelho, M. L.; Ferreira, I. C. F. R. Influence of Gamma Irradiation in the Antioxidant Potential of Chestnuts (Castanea Sativa Mill.) Fruits and Skins. Food Chem. Toxicol. 2011, 49 (9), 1918-1923.

(86) Hussain, P. R.; Suradkar, P.; Javaid, S.; Akram, H.; Parvez, S. Influence of Postharvest Gamma Irradiation Treatment on the Content of Bioactive Compounds and Antioxidant Activity of Fenugreek (Trigonella Foenum-Graceum L.) and Spinach (Spinacia Oleracea L.) Leaves. Innovative Food Sci. Emerging Technol. 2016, 33, 268-281.

(87) Štajner, D.; Milošević, M.; Popović, B. M. Irradiation Effects on Phenolic Content, Lipid and Protein Oxidation and Scavenger Ability of Soybean Seeds. Int. J. Mol. Sci. 2007, 8 (7), 618-627.

(88) Behgar, M.; Ghasemi, S.; Naserian, A.; Borzoie, A.; Fatollahi, H. Gamma Radiation Effects on Phenolics, Antioxidants Activity and in Vitro Digestion of Pistachio (Pistachia Vera) Hull. Radiat. Phys. Chem. 2011, 80 (9), 963-967.

(89) Oufedjikh, H.; Mahrouz, M.; Amiot, M. J.; Lacroix, M. Effect of $\gamma$-Irradiation on Phenolic Compounds and Phenylalanine AmmoniaLyase Activity during Storage in Relation to Peel Injury from Peel of Citrus Clementina Hort. Ex. Tanaka. J. Agric. Food Chem. 2000, 48 (2), 559-565.

(90) Kim, J. W.; Lee, B. C.; Lee, J. H.; Nam, K. C.; Lee, S. C. Effect of Electron-Beam Irradiation on the Antioxidant Activity of Extracts from Citrus Unshiu Pomaces. Radiat. Phys. Chem. 2008, 77 (1), 8791.

(91) Conceição, N.; Albuquerque, B. R.; Pereira, C.; Corrêa, R. C. G.; Lopes, C. B.; Calhelha, R. C.; Alves, M. J.; Barros, L.; C F R Ferreira, I. By-Products of Camu-Camu [Myrciaria Dubia (Kunth) McVaugh] as Promising Sources of Bioactive High Added-Value Food Ingredients: Functionalization of Yogurts. Molecules 2020, 25 (1), 70.

(92) da Silva Veloso, F.; Caleja, C.; Calhelha, R. C.; Pires, T. C. S.; Alves, M. J.; Barros, L.; Genena, A. K.; Barreira, J. C. M.; Ferreira, I. C. F. R. Characterization and Application of Pomegranate Epicarp Extracts as Functional Ingredients in a Typical Brazilian Pastry Product. Molecules 2020, 25 (7), 1481.

(93) Hallabo, S. A. S.; Helmy, S. A.; Elhassaneen, Y.; Shaaban, M. Utilization of Mango, Onion and Potato Peels as Sources of Bioactive Compounds in Biscuits Processing. Biosci. Res. 2018, 15 (4), 36473657. 
(94) Mildner-Szkudlarz, S.; Zawirska-Wojtasiak, R.; Szwengiel, A.; Pacyński, M. Use of Grape By-Product as a Source of Dietary Fibre and Phenolic Compounds in Sourdough Mixed Rye Bread. Int. J. Food Sci. Technol. 2011, 46 (7), 1485-1493.

(95) Bonilla, J.; Vargas, F. C.; de Oliveira, T. G.; da Aparecida Makishi, G. L.; do Amaral Sobral, P. J. Recent Patents on the Application of Bioactive Compounds in Food: A Short Review. Current Opinion in Food Science; Elsevier Ltd: 2015; pp 1-7. DOI: $10.1016 /$ j.cofs.2015.05.012.

(96) WO2014013122. Polyphenol Extract from White-Grape Residue. https://patentscope.wipo.int/search/en/detail.jsf?docId= $\mathrm{W} O 2014013122 \& \mathrm{rec} \mathrm{Num}=201$ \& d o c A n = ES2013070526\&queryString $=($ ANA:ES $) \& \operatorname{maxRec}=26774$ (accessed Sept 8, 2020).

(97) Lores Aguin, M.; Garcia Jares, C.; Alvarez Casas, M.; Llompart, M. Polyphenol Extract from White-Grape Residue. January 23, 2014.

(98) US20150282507A1. Extrusion of agro-food industry byproducts and protein concentrates into value-added foods. https:// patents.google.com/patent/US20150282507A1/en (accessed Sept 8, 2020).

(99) Bravo, J.; Juániz, I.; Monente, C.; Caemmerer, B.; Kroh, L. W.; De Peña, M. P.; Cid, C. Evaluation of Spent Coffee Obtained from the Most Common Coffeemakers as a Source of Hydrophilic Bioactive Compounds. J. Agric. Food Chem. 2012, 60 (51), 1256512573.

(100) De Freitas, T. B.; Santos, C. H. K.; da Silva, M. V.; Shirai, M. A.; Dias, M. I.; Barros, L.; Barreiro, M. F.; Ferreira, I. C. F. R.; Gonçalves, O. H.; Leimann, F. V. Antioxidants Extraction from Pinhão (Araucaria Angustifolia (Bertol.) Kuntze) Coats and Application to Zein Films. Food Packag. Shelf Life 2018, 15, 28-34.

(101) Santos, C. H. K.; Baqueta, M. R.; Coqueiro, A.; Dias, M. I.; Barros, L.; Barreiro, M. F.; Ferreira, I. C. F. R.; Gonçalves, O. H.; Bona, E.; da Silva, M. V.; Leimann, F. V. Systematic Study on the Extraction of Antioxidants from Pinhão (Araucaria Angustifolia (Bertol.) Kuntze) Coat. Food Chem. 2018, 261, 216.

(102) Zan, R. A.; Fernandes, Â.; Jedoz, S.; Oludemi, T.; Calhelha, R. C.; Pires, T. C. S. P.; Alves, M. J.; Martins, R. C. C.; Barros, L.; Ferreira, I. C. F. R. Bioactive Properties and Phytochemical Assessment of Bacupari-Anão (Garcinia Brasiliensis Mart.) Leaves Native to Rondônia, Brazil. Food Funct. 2018, 9 (11), 5621-5628.

(103) Souilem, F.; Dias, M. I.; Barros, L.; Calhelha, R. C.; Alves, M. J.; Harzallah-Skhiri, F.; Ferreira, I. C. F. R. Phenolic Profile and Bioactive Properties of Carissa Macrocarpa (Eckl.) A.DC.: An in Vitro Comparative Study between Leaves, Stems, and Flowers. Molecules 2019, 24 (9), 1696.

(104) Dias, M.; Caleja, C.; Pereira, C.; Calhelha, R. C.; Kostic, M.; Sokovic, M.; Tavares, D.; Baraldi, I. J.; Barros, L.; Ferreira, I. C. F. R. Chemical Composition and Bioactive Properties of Byproducts from Two Different Kiwi Varieties. Food Res. Int. 2020, 127, 108753.

(105) Melgar, B.; Dias, M. I.; Ciric, A.; Sokovic, M.; Garcia-Castello, E. M.; Rodriguez-Lopez, A. D.; Barros, L.; Ferreira, I. C. R. F. Bioactive Characterization of Persea Americana Mill. by-Products: A Rich Source of Inherent Antioxidants. Ind. Crops Prod. 2018, 111, 212-218.

(106) Pavlović, A. V.; Papetti, A.; Zagorac, D. Č. D.; Gašić, U. M.; Mišić, D. M.; Tešić, Ž. L.; Natić, M. M. Phenolics Composition of Leaf Extracts of Raspberry and Blackberry Cultivars Grown in Serbia. Ind. Crops Prod. 2016, 87, 304-314.

(107) Albuquerque, B. R.; Pereira, C.; Calhelha, R. C.; José Alves, M.; Abreu, R. M. V.; Barros, L.; Oliveira, M. B. P. P.; Ferreira, I. C. F. R. Jabuticaba Residues (Myrciaria Jaboticaba (Vell.) Berg) Are Rich Sources of Valuable Compounds with Bioactive Properties. Food Chem. 2020, 309, 125735.

(108) Xu, G.; Ye, X.; Chen, J.; Liu, D. Effect of Heat Treatment on the Phenolic Compounds and Antioxidant Capacity of Citrus Peel Extract. J. Agric. Food Chem. 2007, 55, 330-335.

(109) Barreto, J. C.; Trevisan, M. T. S.; Hull, W. E.; Erben, G.; De Brito, E. S.; Pfundstein, B.; Rtele, G. W.; Spiegelhalder, B.; Owen, R. W. Characterization and Quantitation of Polyphenolic Compounds in
Bark, Kernel, Leaves, and Peel of Mango (Mangifera Indica L.). J. Agric. Food Chem. 2008, 56, 5599-5610. 